\title{
Mental Health and the Media: From Illness to Wellbeing
}

\author{
Atanasova, D., Koteyko, N., Brown, B. \& Crawford, P.
}

\begin{abstract}
The media are a main source of information about mental health for many people and an evergrowing body of literature is evaluating their coverage of the topic. To help keep track of such research, several comprehensive but now dated literature reviews have been published. We assess more recent studies (2007-2017) and suggest future directions by integrating (1) the 'circuit of mass communication' model from media and communication studies which posits that production, content and reception need to be analysed for an in-depth understanding of the media, (2) the holistic view of mental health as comprising both illness and wellbeing and (3) the critical psychiatry literature questioning the assumptions underlying psychiatric knowledge and practice. We find that recent studies have focused on content and 'the illness side' of mental health by examining the representation of particular mental disorders and events involving individuals with specific diagnoses. We identify as a promising development the growing interest in 'the wellbeing side' of mental health whereby authors have started to analyse recovery messages. We invite more production and reception research and more critical content studies which use diagnostic labels cautiously and analyse the representation of people with mental health problems as the victims of violence.
\end{abstract}

literature review, media, mental health, recovery, mental illness, mental wellbeing

\section{Introduction}

Researchers have long been preoccupied with the relationship between the media and conceptions of social reality (Anderson, 1997) and where mental health is concerned studies have shown that public attitudes can be informed by media content (e.g. Thornton \& Wahl, 1996). The treatment of mental health in the media has thus received significant research attention, as reflected in the number of comprehensive literature reviews of original studies that have been published over the years (e.g. Coverdale \& Nairn, 2006; Klin \& Lemish, 2008; Nairn, 2007; Pirkis et al., 2006; Stout et al., 2004; Stuart, 2006; Wahl, 1992, 2003). A common theme in these literature reviews has been that people with mental disorders are depicted negatively across media types (films, magazines, newspapers, television, radio) and genres (from fictional genres such as comedy and drama to factual genres such as news and current affairs). They tend to be presented as dangerous and violent regardless of their diagnosis (e.g. depression or psychosis) and despite evidence that people with mental disorders are more likely to be the victims of crime rather than the perpetrators of acts of violence (Teplin et al., 2005). Such depictions may promote stigmatising generalisations about negative behaviour across the different diagnoses, impair help-seeking by people with mental health difficulties and interfere with their social integration (Jorm, 2000).

As the major literature reviews referenced above are now at best ten years old, we summarise the key findings of studies that have been published over the most recent full decade $(2007-2017)^{\mathrm{i}}$ and identify directions for future research. We focus on journal articles that have become available since the publication of the latest, comprehensive literature review by Klin \& Lemish (2008) which analysed original studies available as of the end of 2006. When reviewing this body of research, we integrate: (1) the 'circuit of mass communication' model from media and communication studies which posits that the media can be best understood through the combined analysis of production, content and reception (e.g. McQuail, 2006); (2) the World Health Organization's (2018) definition of mental health as a holistic construct which involves both treating disorder and promoting wellbeing and 'recovery' - understood as 
the notion that people with mental disorders can live satisfying, hopeful and contributing lives within the limitations of their condition; and (3) the growing critical psychiatry literature questioning the assumptions underlying psychiatric knowledge and practice - particularly in terms of the problems of diagnosis and of violence and coercion in treatment (e.g. Double, 2002; Thomas, 2013).

We find that recent studies have focused on content and 'the illness side' of mental health. That is, how particular mental disorders and events involving individuals with specific diagnoses have been represented. We identify as a promising development the growing interest in 'the wellbeing side' of mental health whereby authors have started to examine media messages about recovery. We invite further research into production and reception as well as more critical approaches to the study of content which use diagnostic labels with caution and analyse how the media represent people with mental health problems when they have been the victims of violence. These points are further elaborated below. Following the structure of the 'circuit of mass communication' model, the next section is dedicated to production studies. We then review content and reception research. In each section, we summarise the key focus of existing studies and identify future directions. We conclude with a final summary of the main themes from the reviewed literature, key recommendations for further analysis and a note on limitations.

\section{Production: Recent Research and Future Directions}

Echoing the conclusions of past literature reviews, production remains the most underresearched area where mental health and the media are concerned (e.g. Klin \& Lemish, 2008; Stout et al., 2004). Recent production studies have followed two main lines of research: (1) examining the sources of information for journalists and the possible link between sources and the dominant messages about mental health conveyed in news articles; and (2) analysing the news values driving mental health reporting.

Both the study of sources and news values - the answer to the question 'what is news' (Galtung \& Ruge, 1965) - are prominent themes in production studies in general (e.g. Caple, 2018). Along with other factors (e.g. the availability of a reporter), sources and news values are understood to influence news production and message content (e.g. Caple, 2018). General research has also identified an authority-orientation in the news with preference for official sources (such as representatives from government, industry and professional organisations) leaving 'ordinary' people rarely quoted (Hansen, 1991); and a negativity-orientation meaning that events and issues that invoke the news value of 'bad news' are given preference over more positive ones (Bell, 1991).

\section{Sources}

Some of the scholarship on the subject of source use in mental health reporting has suggested that the persistence of stigmatising depictions in terms of dangerousness and violence may be related to the infrequent inclusion of individuals with mental health difficulties as sources in news articles (e.g. Coverdale et al., 2002; Henson et al., 2009). Results from other studies have challenged the expectation that incorporating the voices of people with mental disorders will improve news representations. Nawková et al. (2012: 36) have found that even when 'individuals with mental disorders appeared as sources of information' in newspaper and magazine articles, representations 'tended to be negative'. A possible explanation is that people who have experienced or are currently experiencing mental health difficulties may have internalised the stereotypes attached to their diagnoses (Watson et al., 2007). The inconclusiveness of the above findings underscores the importance of source analysis, as it cannot be assumed that the incorporation of the voices of people with mental health difficulties will automatically result in more positive coverage about mental health. 
In addition to the link between sources and messages, researchers have also been interested in the quotation patterns that emerge from the analysis of news content. Studies have generally concluded that people with mental health problems and their family members and friends have been rarely featured as news sources (Goulden et al., 2011; Kesic et al., 2012; Whitley \& Berry, 2013), but longitudinal studies provide some evidence that the tendency for low inclusion of the voices of individuals with mental health difficulties is improving over time (Thornicroft et al., 2013).

The rise of social media with low barriers to entry (everyone can, in principle, start a blog or a Twitter account), allows 'ordinary' people with mental health difficulties to produce content and make their voices heard while bypassing mainstream media (Newman et al., 2012). Social media (particularly Twitter) offers opportunities for grass-roots mental health advocacy (e.g. Koteyko \& Atanasova, 2018) and blogs written by individuals experiencing mental health problems are regarded as important sources of information and sites of self-(re)presentation (e.g. Campbell, 2018). While researchers have started to analyse mental health and social media, the focus has been on assessing social media's utility for detecting and diagnosing mental health disorders and for providing support (see the section Social Media Content). How people with mental health difficulties present their experiences and construct identities on social media and what issues they advocate are issues that deserve more attention.

\section{News Values}

Recent production research has also been interested in how journalists decide what counts as news and what makes one event or issue related to mental health more likely to be reported as news than another. Drawing on the theory of news values, Everett (2015) has analysed how newspapers have represented mental illness in terms of the tone of reporting (positive or negative) and the news values that appeared to drive the coverage. '[A]n overwhelming majority of articles' were found to have been negative in tone and the news value of 'bad news' was identified as the prime news value in the studied sample (Everett, 2015: 306), leading to the conclusion that 'mental illness [was] only newsworthy in limited and often negative circumstances' (Everett, 2015: 309).

This preference for negativity is consistent with the general observation that 'bad news' is the 'basic news value' driving reporting (Bell, 1991: 156). The media's focus on negativity has more recently been undergoing re-evaluation, as proponents of a growing 'constructive journalism' movement challenge the notion that something is not news unless it is negative (Gyldensted, 2015; Haagerup, 2017). 'Constructive journalism' can be understood as 'an emerging form of journalism that involves applying positive psychology techniques to news processes (...) to create productive and engaging coverage' (McIntyre \& Gyldensted, 2017: 20). It seeks to redefine the existing dominant negative news angle by adding a solutionsfocused perspective to reporting on important societal issues, with solutions being inherently more positive and therefore more aligned with the news value of 'good news'. Endorsed by a rising number of dedicated media outlets (e.g. Positive News, Perspective Daily) and existing news organisations (e.g. BBC World Hacks), this ongoing reassessment of the status of 'bad news' as the prime news value driving production has potentially significant implications for mental health-related media coverage.

Mindful of these themes in existing research, we recommend the continued study of sources in terms of quotation patterns and links between sources and messages about mental health as well as more research on 'ordinary' people as sources and producers of content about mental health through social media. We also invite analyses of the representation of mental health in media outlets practicing constructive journalism. Finally, studies have approached the analysis of both sources and news values by examining media content (a tendency that is not unique to mental health research, see Caple (2018)). By this we mean that researchers have 
examined the content of news articles to make conclusions about the news values that may have motivated the coverage and the use of sources. Future production research could therefore engage different methods including observations, interviews and other ethnographic and netnographic approaches to explore the questions of newsworthiness and source preference.

\section{Content: Recent Research and Future Directions}

Recent research has been primarily concerned with analysing the content of various media types. The tendency to focus on content was first observed by Wahl in 1992 (in the earliest published comprehensive literature review of original studies) and has remained a recurrent theme in major subsequent literature reviews (e.g. Coverdale \& Nairn, 2006; Klin \& Lemish, 2008; Nairn, 2007; Pirkis et al., 2006; Stout et al., 2004; Stuart, 2006; Wahl, 2003). While the focus on content has been identified as a weakness of the research on mental health and the media (e.g. Wahl, 1992), it is largely agreed that studies of media content can be beneficial both on their own and as a first step towards engaging with production and reception analysis (Devereux, 2014). When analysing content, recent studies have: (1) focused on 'the illness side' of mental health; (2) identified recurrent stigmatising representations of people with mental health difficulties as dangerous and violent; and (3) increasingly analysed social media content in addition to more traditional media types.

\section{'The Illness Side'}

The focus on illness is evident in studies that have: (a) analysed the depiction of specific disorders such as dementia (e.g. van Gorp \& Vercruysse, 2012), depression (e.g. Bengs et al., 2008; Cavazos-Rehg et al., 2016; Clarke, 2009, 2011; Moreno et al., 2011, 2012; Tobin \& Lyddy, 2014; Wang \& Liu, 2016; Yang \& Mu, 2015; Zhang et al., 2015, 2016), obsessivecompulsive disorder (e.g. Pavelko \& Myrick, 2015), post-traumatic stress disorder (e.g. Houston et al., 2016; Salzmann-Erikson \& Hiçdurmaz, 2017; Wu, 2016) and schizophrenia (e.g. Boke et al., 2007; Chopra \& Doody, 2007; Clement \& Foster, 2008; Magliano et al., 2011); (b) examined violent events including homicides, mass shootings, suicides and forceful encounters with the police involving individuals with specific diagnoses (e.g. Carpiniello et al., 2007; Ion et al., 2014; Kalucy et al., 2011; Kesic et al., 2012; McGinty et al., 2014); or (c) explored media messages about 'mental illness' often treating the term as synonymous with psychosis and other diagnoses of serious mental illness (e.g. Aragonès et al., 2014; Atilola \& Olayiwola, 2013; Bilić and Georgaca 2007; Clarke 2016; Diefenbach \& West, 2007; Everett, 2015; Goulden et al., 2011; McGinty et al., 2016; Mfoafo-M'Carthy et al., 2016; Nawková et al., 2012; Parrott \& Parrott, 2015; Rasmussen \& Ewoldsen, 2016; Thornicroft et al., 2013; Whitley \& Berry, 2013).

The latter tendency to equate 'mental illness' to diagnoses of serious mental illness is apparent in the keyword sourcing practices of studies which have combined general search terms such as 'mental illness', 'mental disorder', 'psychiatric disorder' and 'psychiatric illness' with the names of diagnoses of serious mental illness including 'bipolar', 'psychopathy', 'psychosis' and 'schizophrenia' to source relevant content (e.g. Aragonès et al., 2014; Bilić \& Georgaca, 2007; Goulden et al., 2011; McGinty et al., 2014, 2016; Parrott \& Parrott, 2015; Whitley \& Berry, 2013). Such use of labels denoting specific diagnoses alongside general terms for 'mental illness' demonstrates little sensitivity to the uncertainties of diagnosis that have been expressed and problematised in a growing body of critical psychiatry literature (e.g. Double, 2002; Thomas, 2013). While the media reflect on the ongoing discussions around psychiatric diagnostic criteria, assess the evidence base to support a biological basis for psychiatric diagnoses and consider the danger that single-word diagnoses may disguise uncertainty around psychiatric disease entities (e.g. Greenberg, 2013), recent studies of mental health and the media have not engaged with media content of this type. 
Focusing on 'the illness side' of mental health, researchers have consequently paid little attention to 'the wellness side'. Exceptions include studies by Aragonès et al. (2014), Atanasova et al., (2017), Goulden et al. (2011), Henson et al. (2009), Kenez et al. (2015), McGinty et al. (2016), Thornicroft et al. (2013) and Whitley \& Berry (2013). Such studies typically provide little detail regarding the precise content of recovery messages and tend to be limited to giving quantitative information about the prevalence of recovery themes. A more indepth analysis of both the qualitative characteristics and frequency of recovery messages in newspapers is available in Atanasova et al.'s (2017) study, which identified a dominant theme of 'recovery' emphasising that mental illness can be treated similarly to physical illness including through arts participation. The concept of 'recovery' is built on a strong belief that it is possible for people with mental disorders to regain a meaningful life despite persistent symptoms (World Health Organization, 2018). Referred to as a journey and a process, recovery calls for hope, optimism and commitment from people with mental disorders, their families, mental health professionals and the wider community to look beyond the limits imposed by illness and to help people with mental health difficulties achieve their goals and manage their lives (Jacob, 2015). The presence of positive, hopeful, recovery-focused messages in the media is a potentially significant development, as it can contribute to an environment that is more conductive to these aims.

\section{Stigma}

A recurrent theme across recent research is that the media are disproportionately likely to associate individuals with mental health problems with dangerousness and violence compared to their statistical risk (e.g. Aragonès et al., 2014; Bilić \& Georgaca, 2007; Boke et al., 2007; Clement \& Foster, 2008; Diefenbach \& West, 2007; Dubugras et al., 2011; Everett, 2015; Goulden et al., 2011; Kesic et al., 2012; Magliano et al., 2011; McGinty et al., 2016; MfoafoM'Carthy et al., 2016; Nawková et al., 2012; Parrott \& Parrott, 2015; Thornicroft et al., 2013; Whitley \& Berry, 2013). This tendency holds across geographies and has manifested in studies from Africa (e.g. Mfoafo-M'Carthy et al., 2016), Europe (e.g. Aragonès et al., 2014; Bilić \& Georgaca, 2007; Boke et al., 2007; Clement \& Foster, 2008; Everett, 2015; Goulden et al., 2011; Magliano et al., 2011; Nawková et al., 2012; Thornicroft et al., 2013) and North America (Diefenbach \& West, 2007; McGinty et al., 2016; Parrott \& Parrott, 2015; Whitley \& Berry, 2013). Such depictions might sustain existing stigmatising attitudes towards people with mental health difficulties and encourage beliefs that they should be confined and managed rather than integrated in communities. However, there are also signs that stigma in the media may be improving. Atanasova et al. (2017) for example have identified the theme of stigma in newspaper coverage about mental health, but this was on account of discussing stigma as a problem that needs to be addressed, not the media per se engaging in stigmatising depictions.

A less researched topic within the above theme of violence involves violence towards individuals with mental health difficulties - particularly that experienced within mental health services. The critical psychiatry literature has been long concerned with the coercion, abuse and neglect of people with mental health difficulties in psychiatry (e.g. Thomas, 2013) and the media has been reporting on such cases (e.g. Yeung, 2017). This aspect of violence and mental health has however attracted little research attention.

\section{Social Media Content}

In addition to more traditional media types - films, magazines, (online) newspapers and television - research has increasingly examined the content of social media websites. This is a development from previous literature reviews (e.g. Klin \& Lemish, 2008), which have observed a scarcity of social media studies. From a public health perspective, social media has attracted much interest as an opportunity for health surveillance and disease detection (Yang 
et al., 2013). Studies on social media and mental health have been similarly concerned with the potential of social media analysis for the detection, diagnosis and targeting of individuals who might need help. There has been particular interest in depression which has been on the rise globally (World Health Organization, 2017), but often remains undiagnosed and untreated (Kessler et al., 2003). Examples of this type of research include Cavazos-Rehg et al.'s (2016), Moreno et al.'s $(2011,2012)$ and Yang \& Mu's (2015) studies of tweets and Facebook posts to detect and diagnose depression. Another common line of research where social media and health are concerned has been how individuals seek and provide support online in the case of highly stigmatised conditions where it may be difficult to tell one's story and seek help faceto-face (Naslund et al., 2016; Salzmann-Erikson \& Hiçdurmaz, 2017).

Overall, much research has focused on the study of content, but gaps remain. We recommend that future studies conduct more critical research of media content which uses diagnostic labels with caution and analyses how people with mental health difficulties have been represented when they have been the victims of violence. We also welcome more in-depth analyses of recovery themes that go beyond reports of prevalence. Such future focus is warranted by the presence of recovery messages in the media (as demonstrated through the above studies); current trends in journalism (and particularly, the constructive journalism movement, which seeks to introduce a more solutions-oriented focus to news reporting); and the increasing prominence of the notion of recovery in the mental health care discourses in many parts of the world (Smith-Merry \& Sturdy, 2013).

\section{Reception: Recent Research and Future Directions}

Recently conducted reception studies have evaluated people's attitudes towards individuals with mental health difficulties in response to exposure to (1) mainstream and (2) social media messages. Such research has found that there is an association between negative media depictions and negative attitudes towards individuals with mental disorders but equally, that positive, recovery-focused messages in the media can improve public attitudes. These effects of media messages have been evaluated through experimental and survey designs as well as by using more novel approaches to analyse comment chains on social media to understand opinion expression.

\section{Mainstream Media Exposure}

Using a survey design, Diefenbach \& West (2007) have demonstrated how greater exposure to stigmatising portrayals of individuals with mental disorders on television (depictions as more likely to be violent criminals than other characters) correlated with beliefs that locating mental health services in residential neighbourhoods will endanger residents. Demonstrating how media representations may not only sustain but also alleviate stigma, Corrigan et al. (2013) randomly assigned experiment participants to read one of three news articles: a positive one (presenting research evidence that people with serious mental disorders can recover); a negative one (discussing violence by people with mental disorders); or a neutral article (on dental hygiene). Before and after measures of participants' attitudes showed that reading the violence-related news article led to endorsing greater coercion measures and suggesting that people with serious mental illness should be forced into treatment but also, that the recoveryfocused news article reduced stigma. Using a similar experimental design, Rubenking \& Bracken (2015) exposed participants to positive, negative and neutral episodes featuring a character with schizophrenia and found that exposure to violent, mediated portrayals of fictional characters with mental disorders increased stigmatising attitudes, while exposure to sympathetic portrayals decreased stigma.

\section{Social Media Exposure}


Experimental designs have also been employed to evaluate the effects of social media messages on attitudes towards people with mental disorders. Pavelko \& Myrick (2015) conducted an online experiment to test the impact of trivialised discussions of obsessive-compulsive disorder in tweets on perceptions of individuals with the condition. Findings indicated that exposure to trivialising tweets (which oversimplified, downgraded and/or mocked the condition) did not have a strong influence on perceptions of people with obsessive-compulsive disorder in terms of changes in the preferred social distance between experiment participants and people with obsessive-compulsive disorder. Taking a different approach, Wang \& Liu (2016) analysed the content of depression-related Weibo posts made by media organisations and public opinion leaders and the content of response posts by followers to understand the original posts' impact on the subsequently expressed views by followers. The study found that the presence of stigmatising ideas in original posts (e.g. suggesting that people with depression are weak, incompetent and/or suicidal) elicited significantly more frequent stigmatising responses from followers. In contrast, only a small percentage of original posts with recovery information elicited stigmatisation in responses suggesting that such information (that is, information that contributes to presenting depression as treatable) can significantly reduce stigmatising beliefs.

Against this background, we recommend more research that investigates the relationship between exposure to more positive media messages about mental health and public attitudes and more studies that seek to apply novel approaches to analyse opinion expression about mental health on social media.

\section{Conclusion}

We reviewed research on mental health and the media that has become available more recently (2007-2017) and found that studies have continued to focus on the analysis of media content. When exploring content, studies have tended to approach the holistic concept of mental health from its 'illness side' analysing depictions of particular diagnoses and events that involve individuals with specific disorders. Such studies have uncovered a dominant across geographies theme of dangerousness which is disproportionate to the occurrence of violent incidents perpetrated by individuals with mental disorders and might sustain stigma. Related to this, we also identified a lack of critical research of media content, which adopts a more reflective view of diagnostic labels and analyses how the media report the problems of psychiatric diagnosis and coercion, abuse and neglect in treatment. As the majority of the more recent studies that we reviewed have focused on 'the illness side' of mental health, we highlighted as a promising direction the growing research on 'the wellbeing side' of mental health which has started to examine the recovery messages present in the media. We finally noted that the focus on content means that there have been relatively few production and receptions studies.

In terms of production, some of the recent research has shown that the inclusion of people with mental disorders as sources in news articles does not necessarily result in more positive coverage of mental health, underscoring the importance of source analysis. Other production studies of the newsworthiness of mental health have found that the news value of 'bad news' is the prime driver of mental health coverage. The traditionally negative coverage of mental health cannot be attributed to news values, as it reflects the wider social reality of the asylum years (Porter \& Wright, 2003). The dismantling of mental asylums across the world and the change of focus in journalistic news values hailed by constructive journalism however highlight important aspects about society's evolving attitudes to both mental health and the media. The negativity-orientation of the media therefore needs revisiting in the light of the growing constructive journalism movement, which seeks to offer more positive, constructive and solutions-focused reporting and the more reflective and positive attitudes to living, working and interacting with people with mental health difficulties (Mind, 2014). While the study of 
sources and news values both provide worthwhile future directions, this type of research is still focused on media content. By this we mean that studies have examined the content of news articles to make conclusions about the news values that may have motivated the coverage and the use of sources. Future production research could therefore engage in observations, interviews and other ethnographic and netnographic research to explore the questions of newsworthiness and source preference. Finally, in a media environment where 'ordinary' people have greater opportunities to have their voices heard while bypassing the mainstream media, we additionally recommend more research into the social media content produced by individuals with mental health difficulties.

In terms of reception, recent research has employed experimental and survey designs to test the possible impact of media messages on attitudes to people with mental disorders. A significant finding here is that just as stigmatising depictions of mental disorders can lead to more negative attitudes, recovery themes can result in less stigmatising, more positive attitudes to people with mental health difficulties. There is more scope for research studying the effects of recovery-focused messages in different media as well as for researchers to experiment with novel methodologies for studying opinion expression on newer, social media websites.

Finally, our literature review has concluded that stigma continues to be a theme across studies of production, content and reception, but we have also identified positive developments which mark a change from earlier surveys of the literature. First, at the production end, growing support for a constructive approach to journalism may mean fewer stigmatising portrayals of mental health. Second, studies of media content show that media outlets are approaching stigma as a problem to be addressed, not only producing stigmatising representations. Last, reception research points to a link between exposure to messages about recovery and a decrease in stigmatising attitudes.

Our findings should be viewed in the light of at least one limitation. While we have sought to be comprehensive, we have focused our survey of the literature on peer-reviewed journal articles. There is therefore a chance that the inclusion of other potentially relevant materials such as books might reveal a different snapshot of the field.

\section{References}

Anderson, A. (1997). Media, culture, and the environment. New Brunswick: Rutgers University Press.

Aragonès, E., López-Muntaner, J., Ceruelo, S., \& Basora, J. (2014). Reinforcing stigmatization: Coverage of mental illness in Spanish newspapers. Journal of Health Communication, 19(11), 1248-1258.

Atanasova, D., Koteyko, N., Brown, B., \& Crawford, P. (2017). Representations of mental health and arts participation in the national and local British press, 2007-2015. Health, doi:10.1177/1363459317708823.

Atilola, O., \& Olayiwola, F. (2013). Frames of mental illness in the Yoruba genre of Nigerian movies: Implications for orthodox mental health care. Transcultural Psychiatry, 50, 442-454.

Bengs, C., Johansson, E., Danielsson, U., Lehti, A., \& Hammarström, A. (2008). Gendered portaraits of depression in Swedish newspapers. Qualitative Health Research, 18(7), 962-973.

Bilić, B., \& Georgaca, E. (2007). Representations of 'mental illness' in Serbian newspapers: A critical discourse analysis. Qualitative Research in Psychology, 4(1-2), 167-186.

Boke, O., Aker, S., Aker, A. A., Sarisoy, G., \& Sahin, A. R. (2007). Schizophrenia in Turkish newspapers. Social Psychiatry and Psychiatric Epidemiology, 42, 457-461. 
Campbell, L. (2018). Best depression blogs of 2018. Retrieved from: https://www.healthline.com/health/depression/best-blogs-of-the-year\#1 (accessed 29 January, 2019).

Caple, H. (2018). News values and newsworthiness. Oxford Research Encyclopedia of Communication, doi:10.1093/acrefore/9780190228613.013.850.

Carpiniello, B., Girau, R., \& Germana Orrú, M. (2007). Mass-media, violence and mental illness. Evidence from some Italian newspapers. Epidemiologia e Psichiatria Sociale, 16(3), 251-255.

Cavazos-Rehg, P. A., Krauss, M. J., Sowles, S., Connolly, S., Rosas, C., Bharadwaj, M., \& Bierut, L. J. (2016). A content analysis of depression-related tweets. Computers in Human Behavior, 54, 351-357.

Chopra, A. K., \& Doody, G. A. (2007). Schizophrenia, an illness and a metaphor: Analysis of the use of the term 'schizophrenia' in the UK national newspapers. Journal of the Royal Society of Medicine, 100, 423-436.

Clarke, J. N. (2009). The portrayal of depression in magazines designed for men. International Journal of Men's Health, 8(3), 202-212.

Clarke, J. N. (2011). Childhood depression and mass print magazines in the USA and Canada: 1983-2008. Child \& Family Social Work, 16, 52-60.

Clarke, J. N. (2016). The portrayal of children's mental health and developmental issues from 1890 to 1920 in mass print magazines in North America. Children \& Society, 30, 3647.

Clement, S., \& Foster, N. (2008). Newspaper reporting on schizophrenia: A content analysis of five national newspapers at two time points. Schizophrenia Research, 98, 178-183.

Corrigan, P. W., Powell, K. J., \& Michaels, P. J. (2013). The effects of news stories on the stigma of mental illness. Journal of Mental Disorders, 201, 179-182.

Coverdale, J. H., \& Nairn, R. (2006). A research agenda concerning depictions of mental illness in children's media. Academic Psychiatry, 30(1), 83-87.

Coverdale, J. H., Nairn, R., \& Claasen, D. (2002). Depictions of mental illness in print media: A prospective national sample. Australian and New Zealand Journal of Psychiatry, 36, 697-700.

Devereux, E. (2014). Understanding the media (3rd ed.). London: SAGE Publications Ltd.

Diefenbach, D. L., \& West, M. D. (2007). Television and attitudes toward mental health issues: Cultivation analysis and the third-person effect. Journal of Community Psychology, 35(2), 181-195.

Double, D. (2002). The limits of psychiatry. BMJ: British Medical Journal, 324(7342), 900904.

Dubugras, M. T., Evans-Lacko, S., \& Mari Jde, J. (2011). A two-year cross-sectional study on the information about schizophrenia divulged by a prestigeous daily newspaper. The Journal of Nervous and Mental Disease, 199(9), 659-665.

Everett, A. (2015). The newsworthiness of mental illness: An exploration of representations of mental health and illness in the UK national press. Journal of Promotional Communications, 3(2), 302-310.

Galtung, J., \& Ruge, M. H. (1965). The structure of foreign news: The presentation of the Congo, Cuba and Cyprus crises in four Norwegian newspapers. Journal of Peace Research, 2(1), 64-90.

Goulden, R., Corker, E., Evans-Lacko, S., Rose, D., Thornicroft, G., \& Henderson, C. (2011). Newspaper coverage of mental illness in the UK, 1992-2008. BMC Public Health, 11, $1-8$. 
Greenberg, G. (2013). The Rats of N.I.M.H. Retrieved from: https://www.newyorker.com/tech/elements/the-rats-of-n-i-m-h (accessed 29 August, 2018).

Gyldensted, C. (2015). From mirrors to movers: Five elements of positive psychology in constructive journalism. Ibadan: GGroup Publishers.

Haagerup, U. (2017). Constructive news (2nd ed.). Aarhus: Aarhus University Press.

Hansen, A. (1991). The media and the social construction of the environment. Media, Culture and Society, 13, 443-458.

Henson, C., Chapman, S., McLeod, L., Johnson, N., McGeechan, K., \& Hickie, I. (2009). More us than them: Positive depictions of mental illness on Australian television news. Australian and New Zealand Journal of Psychiatry, 43, 554-560.

Houston, B. J., Spialek, M. L., \& Perreault, M. F. (2016). Coverage of posttraumatic stress disorder in the New York Times, 1950-2012. Journal of Health Communication, 21, 240-248.

Ion, R., Pegg, S., \& Moir, J. (2014). Nineteenth century newspaper accounts of a murder committed by an inmate of a Scottish asylum. Journal of Forensic Psychiatry and Psychology, 25(2), 164-175.

Jacob, K. S. (2015). Recovery model of mental illness: A complementary approach to psychiatric care. Indian Journal of Psychological Medicine, 37(2), 117-119.

Jorm, A. F. (2000). Mental health literacy. British Medical Journal, 177, 396-401.

Kalucy, M., Rodway, C., Finn, J., Pearson, A., Flynn, S., Swinson, N., Roscoe, A., Da Cruz, D., Appleby, L., \& Shaw, J. (2011). Comparison of British national newspaper coverage of homicide committed by perpetrators with and without mental illness. The Australian and New Zealand Journal of Psychiatry, 45(7), 539-548.

Kenez, S., O’Halloran, P., \& Liamputtong, P. (2015). The portrayal of mental health in Australian daily newspapers. Australian and New Zealand Journal of Public Health, 39(6), 513-517.

Kesic, D., Ducat, L. V., \& Thomas, S. D. M. (2012). Using force: Australian newspaper depictions of contacts between the police and persons experiencing mental illness. Australian Psychologist, 47, 213-223.

Kessler, R. C., Berglund, P., Demler, O., Jin, R., Koretz, D., Merikangas, K. R., Rush, A. J., Walters, E. E., Wang, P. S. (2003). National comorbidity survey replication. The epidemiology of major depressive disorder: Results from the National Comorbidity Survey Replication (NCS-R). JAMA, 289, 3095-3105.

Klin, A., \& Lemish, D. (2008). Mental disorders stigma in the media: Review of studies on production, content, and influences. Journal of Health Communication, 13, 434-449.

Koteyko, N., \& Atanasova, D. (2018). Mental health advocacy on Twitter: Positioning in Depression Awareness Week tweets. Discourse, Context and Media, 25, 52-59.

Magliano, L., Read, J., \& Marassi, R. (2011). Metaphoric and non-metaphoric use of the term 'schizophrenia' in Italian newspapers. Social Psychiatry, 46(10), 1019-1025.

Matthews, D. (2016, July 16). Academics shun books in favour of journal articles. The Times Higher Education. Retrieved from:

https://www.timeshighereducation.com/news/academics-shun-books-in-favour-ofjournal-articles (accessed 29 January, 2019).

McGinty, E. E., Webster, D. W., Jarlenski, M., \& Barry, C. L. (2014). News media framing of serious mental illness and gun violence in the United States, 1997-2012. American Journal of Public Health, doi:10.2105/AJPH.2013.301557.

McGinty, E. E., Kennedy-Hendricks, A., Choksy, S., \& Barry, C. L. (2016). Trends in news media coverage of mental illness in the United States: 1995-2014. Health Affairs, 35(6), 1121-1129. 
McIntyre, K., \& Gyldensted, C. (2017). Constructive journalism: An introduction and practical guide for applying positive psychology techniques to news production. Journal of Media Innovations, 4(2), 20-34.

McQuail, D. (2006). McQuail's mass communication theory (5th ed.). London: Sage.

Mfoafo-M'Carthy, M., Sottie, C. A., \& Gyan, C. (2016). Mental illness and stigma: A 10year review of portrayal through print media in Ghana (2003-2012). International Journal of Culture and Mental Health, 9(2), 197-207.

Mind. (2014). Survey shows greatest improvement in public attitudes to mental health in 20 years. Retrieved from: https://www.mind.org.uk/news-campaigns/news/surveyshows-greatest-improvement-in-public-attitudes-to-mental-health-in-20years/\#.XFyTOFX7SyI (accessed 29 January, 2019).

Moreno, M. A., Jelenchick, L. A., Egan, K. G., Cox, E., Young, H., Gannon, K. E., \& Becker, T. (2011). Feeling bad on Facebook: Depression disclosures by college students on a social networking site. Depression and Anxiety, 28(6), 447-455.

Moreno, M. A., Christakis, D. A., Egan, K. G., Jelenchick, L. A., Cox, E., Young, H., Villiard, H, \& Becker, T. (2012). A pilot evaluation of associations between displayed depression references on Facebook and self-reported depression using a clinical scale. The Journal of Behavioral Health Services \& Research, 39(3), 295-304.

Nairn, R. G. (2007). Media portrayals of mental illness, or is it madness? A review. Australian Psychologist, 42(2), 138-146.

Naslund, J. A., Aschbrenner, K. A., Marsch, L. A., \& Bartels, S. J. (2016). The future of mental health care: Peer-to-peer support and social media. Epidemiology and Psychiatric Sciences, 25(2), 113-122.

Nawková, L., Nawka, A., Adámková, T., Rukavina, T. V., Holcnerová, P., Kuzman, M. R., Jovanović, N., Brborović, O., Bednárová, B., Zuchová, S., Miovský, M., \& Raboch, J. (2012). The picture of mental health/illness in the printed media in three central European countries. Journal of Health Communication, 17(1), 22-40.

Newman, N., Dutton, W. H., \& Blank, G. (2012). Social media in the changing ecology of news: The Fourth and Fifth Estates in Britain. International Journal of Internet Science, 7(1), 6-22.

Parrott, S., \& Parrott, C. T. (2015). Law \& disorder: The portrayal of mental illness in US crime dramas. Journal of Broadcasting and Electronic Media, 59(4), 640-657.

Pavelko, R. L., \& Myrick, J. G. (2015). That's so OCD: The effects of disease trivialization via social media on user perceptions and impression formation. Computers in Human Behavior, 49, 251-258.

Pirkis, J., Warwick Blood, R., Francis, C., \& McCallum, K. (2006). On-screen portrayals of mental illness: Extent, nature, and impacts. Journal of Health Communication, 11(5), 523-541.

Porter, R., \& Wright, D. (2003). The confinement of the insane: International perspectives, 1800-1965. Cambridge: Cambridge University Press.

Rasmussen, E. E., \& Ewoldsen, D. R. (2016). Treatment via television: The relation between watching Dr. Phil and viewers' intentions to seek mental health treatment. Journal of Health Communication, 21(6), 611-619.

Rubenking, B, \& Bracken, C. C. (2015). The dueling influences on stigma toward mental illness: Effects of interpersonal familiarity and stigmatizing mediated portrayals of mental illness on attitudes. Studies in Media and Communication, doi:10.11114/smc.v3i2.1130.

Salzmann-Erikson, M., \& Hiçdurmaz, D. (2017). Use of social media among individuals who suffer from post-traumatic stress: A qualitative analysis of narratives. Qualitative Health Research, 27(2), 285-294. 
Smith-Merry, J., \& Sturdy, S. (2013). Recovery in Scotland: The rise and uncertain future of a mental health social movement. Society and Mental Health, 3(2), 114-132.

Stout, P. A., Villegas, J., \& Jennings, N. A. (2004). Images of mental illness in the media: Identifying gaps in the research. Schizophrenia Bulletin, 30(3), 543-561.

Stuart, H. (2006). Media portrayal of mental illness and its treatments. CNS Drugs, 20(2), 99106.

Teplin, L. A., McClelland, G. M., Abram, K. M., \& Weiner, D. A. (2005). Crime victimization in adults with severe mental illness. Archives of General Psychiatry, 62, 911-921.

Thomas, P. (2013). What is critical psychiatry? Retrieved from: https://www.madinamerica.com/2013/01/what-is-critical-psychiatry/ (16 August, 2018).

Thornicroft, A., Goulden, R., Shefer, G., Rhydderch, D., Rose, D., Williams, P., Thornicroft, G., \& Henderson, C. (2013). Newspaper coverage of mental illness in England 20082011. The British Journal of Psychiatry, 202, 64-69.

Thornton, J. A. A., \& Wahl, O. F. (1996). Impact of a newspaper article on attitudes toward mental illness. Journal of Community Psychology, 24, 17-25.

Tobin, G., \& Lyddy, F. (2014). Media representation of depression in young people: A corpus-based analysis of Irish newspaper coverage. Irish Journal of Psychological Medicine, 31(1), 21-30.

van Gorp, B., \& Vercruysse, T. (2012). Frames and counter-frames giving meaning to dementia: A framing analysis of media content. Social Science \& Medicine, 74, 12741281.

Wahl, O. F. (1992). Mass media images of mental illness: A review of the literature. Journal of Community Psychology, 20, 343-352.

Wahl, O. F. (2003). Depictions of mental illness in children's media. Journal of Mental Health, 12(3), 249-258.

Wang, W. R., \& Liu, Y. (2016). Discussing mental illness in Chinese social media: The impact of influential sources on stigmatization and support among their followers. Health Communication, 31(3), 355-363.

Watson, A. C., Corrigan, P., Larson, J. E., \& Sells, M. (2007). Self-stigma in people with mental illness. Schizophrenia Bulletin, 33, 1312-1318.

Whitley, R., \& Berry, S. (2013). Trends in newspaper coverage of mental illness in Canada: 2005-2010. Canadian Journal of Psychiatry, 58(2), 107-112.

World Health Organization. (2017). Depression: let's talk. Retrieved from: http://www.who.int/mental_health/management/depression/en/ (accessed 8 August, 2018).

World Health Organization. (2018). Mental health: strengthening our response. Retrieved from: http://www.who.int/news-room/fact-sheets/detail/mental-health-strengtheningour-response (accessed 5 August, 2018).

Wu, L. (2016). US media representation of post-traumatic stress disorder: A comparative study of regional newspapers and national newspapers. Journal of Mental Health, doi:10.3109/09638237.2016.1167849.

Yang, Y. T., Horneffer, M., \& DiLisio, N. (2013). Mining social media and web searches for disease detection. Journal of Public Health Research, 28, 2(1), 17-21.

Yang, W., \& Mu, L. (2015). GIS analysis of depression among Twitter users. Applied Geography, 60, 217-23.

Yeung, P. (2017). NHS abuse of mental patients 'endemic'. Retrieved from: https://www.thetimes.co.uk/article/nhs-abuse-of-mental-patients-endemic-wml058tcl (accessed 29 August, 2018). 
Zhang, Y., Jin, Y., Stewart, S., \& Porter, J. (2016). Framing responsibility for depression: How U.S. news media attribute causal and problem-solving responsibilities when covering a major public health problem. Journal of Applied Communication Research, 44(2), 118-135.

Zhang, Y., Jin, Y., \& Tan, Y. (2015). Framing depression: Cultural and organizational influences on coverage of a public health threat and attribution of responsibilities in Chinese news media, 2000-2012. Journalism \& Mass Communication Quarterly, 92(1), 99-120.

\footnotetext{
i To identify relevant research published between 2007 and 2017, we followed three steps. (1) We surveyed Scopus and Web of Science with the keywords 'mental health', 'mental illness' and 'mental wellbeing' (as exact phrases) in combination with 'media'. (2) The abstracts of all returned items were scrutinised against the following criteria: thematic focus on mental health; analysis of media content, the processes leading to content creation and/or the audience reception of media content; the item being an empirical study, not a theoretical essay; the item being published in a peer-reviewed journal. Our focus on journal articles was motivated by considerations relating to peer review rigour (the rigour of peer review in journals is among the most highly regarded in terms of capacity to identify credible, high quality, novel research) and impact (journal articles now make up over $80 \%$ of submissions to the United Kingdom's Research Excellence Framework (UKREF) (Mathews, 2016)). (3) Relevant studies' bibliographies identified at step 1 were examined against the inclusion criteria in step 2 and omitted research was added. This resulted in 47 journal articles on which our review is based.
}

Acknowledgements: This work was supported by the Arts and Humanities Research Council [AH/K003364/1]. 